\title{
Access and participation: What factors influence the provision and utilisation of healthcare services by children with learning disabilities?
}

\section{Dr Anna Rebowska}

\section{Background}

Children with learning disabilities are at increased risk of suffering from a wide range of health conditions comparing with their peers. However a number of studies demonstrated that they are less likely to access a wide range of healthcare services. Recent reports by UK government as well as independent charities working with children and young people with learning disabilities

demonstrated that they are at risk of poor health outcomes as a result of barriers preventing them from accessing most appropriate services.

\section{Methods}

Comprehensive searches were conducted in five databases. Articles were also obtained through review of references, search of grey literature, and contacting experts in the field.
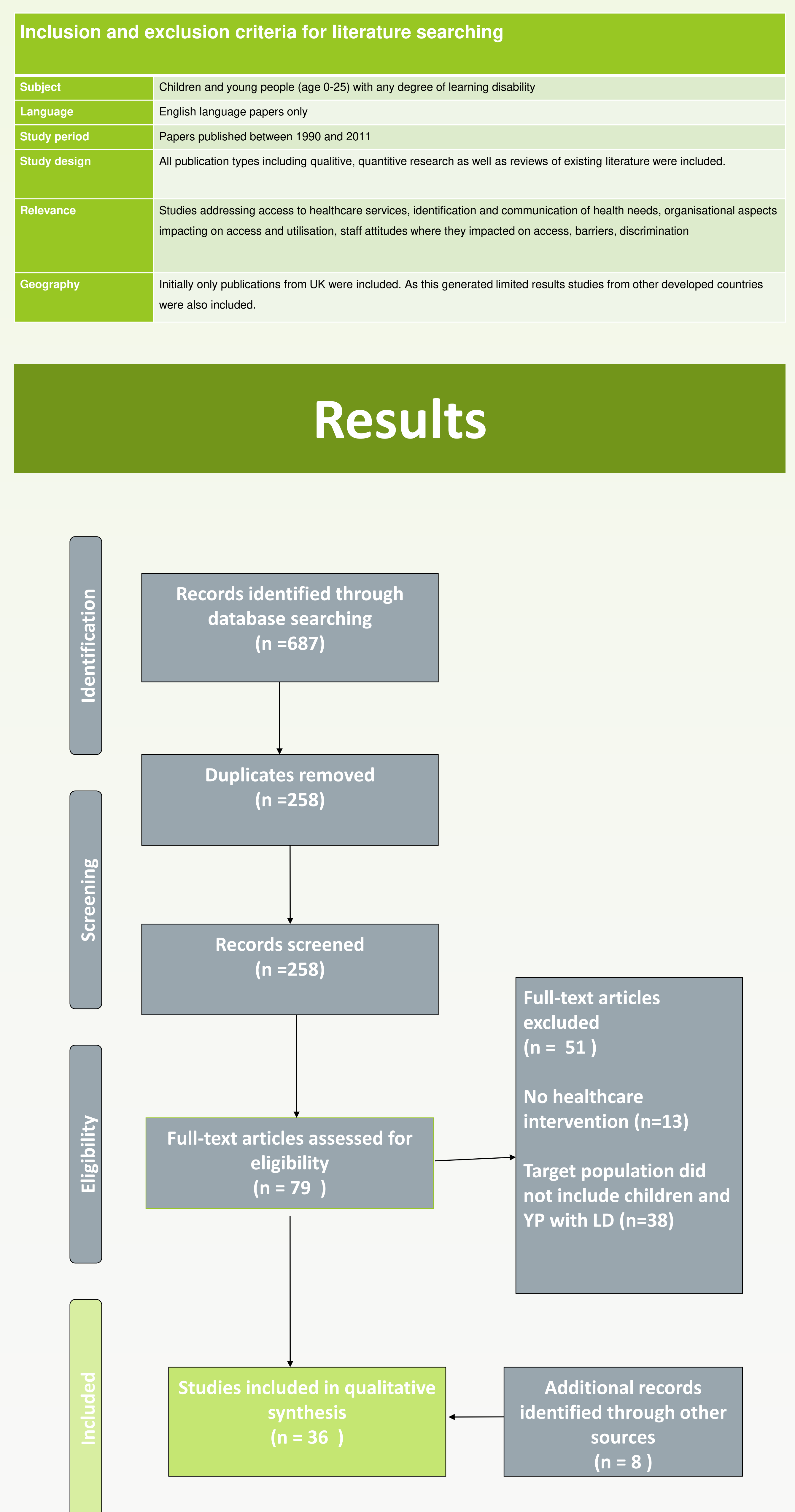

\section{Discussion}

Key findings

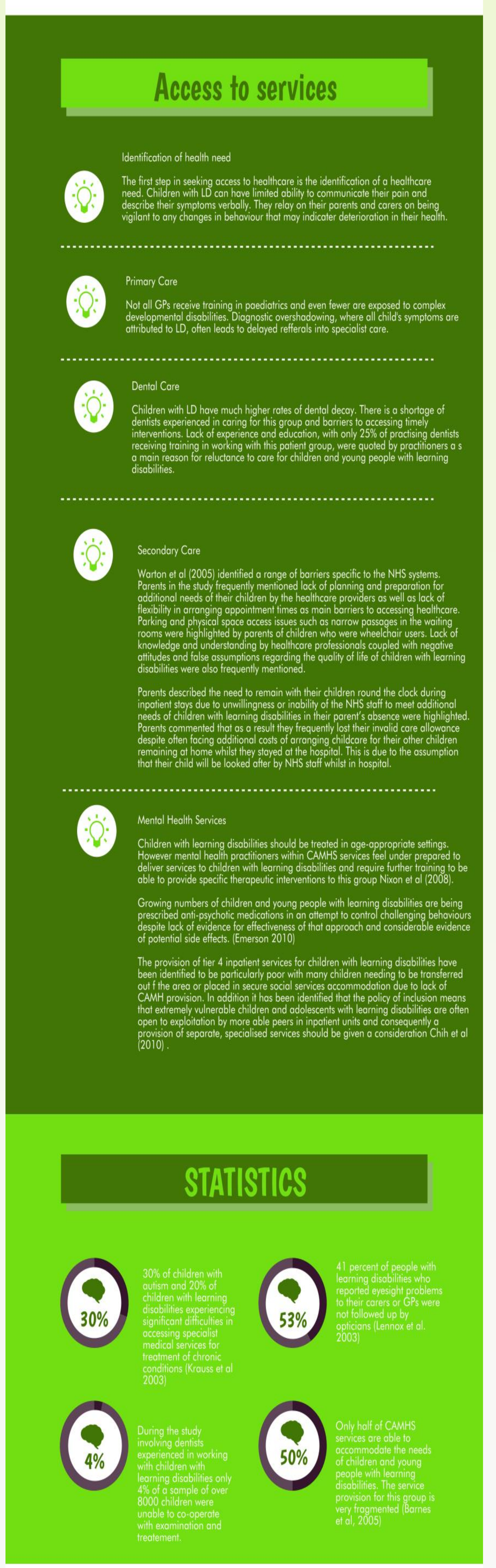

\section{Conclusion}

. Key recommendations from the literature include the need for better information and guidance for parents of children and young people with learning disabilities regarding the range of healthcare services available to them.

Another area identified as needing improvement by a range of studies was training for healthcare professionals. Healthcare staff involved in delivering services to children with $L D$ requires additional training, support and supervision to ensure that unique needs of this group are being met.

There is strong evidence from existing literature that parents and carers play a pivotal role in identifying healthcare needs of children with learning disabilities. However there are no clear explanations regarding at to what point carers consider symptoms to be significant enough to seek professional help and what factors influence that decision.

There is a particular need to revaluate the accessibility of mainstream mental health services and the relationships between general psychiatry and learning disability services.

The review of the literature demonstrated that providers and researchers have been aware of fhany barriers to access and participation faced by children and young people with learning disabilities for many years. Despite that there is a lack of unified, national, evidence based strategy aimed at eliminating those barriers across the NHS services. 